\title{
Incidence and clinical features of kawasaki disease in Catalonia (Spain)
}

\author{
Judith Sanchez-Manubens ${ }^{1,2^{*}}$, Jordi Anton², Fredy Prada ${ }^{3}$, Rosa Bou², Estibaliz Iglesias², Joan Calzada-Hernandez ${ }^{2}$, \\ Vicenç Torrente-Segarra ${ }^{2}$, Samuel Hernandez ${ }^{2}$, Silvia Ricart ${ }^{2}$, Marc Tobeña ${ }^{4}$, Anna Fernandez ${ }^{5}$, \\ Montserrat Gispert-Sauch ${ }^{6}$, Aina Sanchez ${ }^{7}$, Mariona Bonet ${ }^{8}$, Neus Rius $^{9}$, Sonia Corral ${ }^{10}$, Olga Calavia ${ }^{11}$, \\ Kawasaki Disease in Catalonia Working Group
}

From 21st European Pediatric Rheumatology (PReS) Congress

Belgrade, Serbia. 17-21 September 2014

\section{Introduction}

Kawasaki disease (KD) is an acute self-limited systemic vasculitis relatively common in childhood. In Japan, last published survey shows an incidence up to $239.6 / 10^{5}$ children $<5$ years old (yo). In Madrid (Spain) a retrospective study with no well defined reference area showed an incidence of $15.1 / 10^{5}$ children $<5 y$.

\section{Objectives}

To ascertain the incidence and clinical features of KD in Catalonia, autonomous region in northeast Spain with 7.5 million inhabitants.

\section{Methods}

Observational population-based study including all Catalan hospitals with Pediatric Units, both public and private management. Retrospective data retrieval was performed for the last 10 years (2004-2013). The presence of coronary aneurysms (CA) in echocardiology was based in the body surface area according to the American Heart Association.

\section{Results}

Data from 399 patients from 33 different hospitals was analyzed. Of those, $233(58.4 \%)$ patients had complete $\mathrm{KD}, 159$ (39.8) incomplete KD and 7 (1.7\%) were considered atypical $\mathrm{KD}$. The mean annual incidence was $3.5 / 10^{5}$ children $<14$ yo and $8 / 10^{5}$ children $<5$ yo (mean age $37 \pm 33$ months $(\mathrm{m})$, range $1.3-191.3 \mathrm{~m})$. KD was more frequent among boys $(59.6 \%, \mathrm{p}<0.01)$. Mean delay

'Rheumatology Unit, Department of Pediatrics, Hospital Parc Taulí, Sabadell, Spain

Full list of author information is available at the end of the article between onset of the disease and diagnostic was $7.2 \pm 5.3$ days. Ethnic distribution was: Caucasian 279 patients(69.9\%), North African 26 (6.5\%), Amerindian 21 (5.2\%), Asian 14 (3.5\%) and Sub-Saharan 4 (1\%). Ethnicity was not available in 55 (13.8\%) patients. Distribution of classical manifestations for KD was: fever in $100 \%$ of patients, changes in extremities $40.3 \%$ (desquamation in $31 \%$ of them), exanthema $84.2 \%$, conjunctival injection $79.7 \%$, changes in lips and oral cavity $55.6 \%$ and lymphadenopathy $28.8 \%$. Other clinical findings reported were: sterile pyuria in $80(20 \%)$ patients, nausea and vomiting in $96(24 \%)$, abdominal pain in $85(21.3 \%)$, gallbladder distention in $14(3.5 \%)$, transaminase elevation in $120(30 \%)$, jaundice in $21(5.1 \%)$, irritability in $118(29.5 \%)$, aseptic meningitis in 16(4\%), sensorineural hearing loss in 2 patients, uveitis in $11(2.7 \%)$ and arthritis or arthralgia in 55(13.8\%). Cardiologic findings were: perivascular brightness of the coronary wall in $42(10.5 \%)$ patients, pericarditis in 9(2.3\%), myocarditis in 4(1\%), mitral regurgitation in 28 (7\%) and CA in 53 patients(13.3\%), 26(49\%) of them disappearing before the $2^{\text {nd }}$ month after the onset of KD. 4 patient had giant CA. Intravenous immunoglobulin (IVIG) was administered in $389(97.5 \%)$ patients with response to the $1^{\text {st }}$ dose in $332(83.2 \%)$. Day of IVIG administration was $7.5 \pm 3.1$. Other treatment plans were: $2^{\text {nd }}(69 \%$ response) and $3^{\text {rd }}$ IVIG doses, oral or iv corticosteroids and abciximab (administered in 3 of the patients with giant CA). $97.7 \%$ of patients received anti-platelet dose aspirin in the convalescent phase.

\section{Conclusion}

This is the first population-based study on the epidemiology of KD in Catalonia (Spain). It seems to be a higher incidence of $\mathrm{CA}$ in our cohort despite high rates 
of treatment response. Further analysis is required. Incidence rates, other clinical features and treatment plans are similar to dose described in studies in other European countries.

\section{Disclosure of interest}

None declared.

\section{Authors' details}

'Rheumatology Unit, Department of Pediatrics, Hospital Parc Taulí, Sabadell, Spain. ${ }^{2}$ Rheumatology Unit, Department of Pediatrics, Hospital Sant Joan de Déu, Esplugues de Llobregat, Spain. ${ }^{3}$ Cardiology Department, Hospital Sant Joan de Déu, Esplugues de Llobregat, Spain. ${ }^{4}$ Pediatrics Department, Hospital Vall d'Hebron, Barcelona, Spain. ${ }^{5}$ Pediatrics Department, Hospital Arnau de Vllanova, Lleida, Spain. ${ }^{6}$ Pediatrics Department, Hospital Josep Trueta, Girona, Spain. ${ }^{7}$ Pediatrics Department, Consorci Sanujitari de Terrassa, Terrassa, Spain. ${ }^{8}$ Pediatrics Department, Hospital del Mar, Barcelona, Spain. ${ }^{9}$ Pediatrics Department, Hospital Sant Joan de Reus, Reus, Spain. ${ }^{10}$ Pediatrics Department, Hospital General de Granollers, Granollers, Spain. ${ }^{11}$ Pediatrics Department, Hospital Joan XIII, Tarragona, Spain.

Published: 17 September 2014

doi:10.1186/1546-0096-12-S1-P123

Cite this article as: Sanchez-Manubens et al: Incidence and clinical features of kawasaki disease in Catalonia (Spain). Pediatric Rheumatology 2014 12(Suppl 1):P123.

\section{Submit your next manuscript to BioMed Central} and take full advantage of:

- Convenient online submission

- Thorough peer review

- No space constraints or color figure charges

- Immediate publication on acceptance

- Inclusion in PubMed, CAS, Scopus and Google Scholar

- Research which is freely available for redistribution

Submit your manuscript at www.biomedcentral.com/submit
C Biomed Central 